\title{
A 'DIDACTIZAÇÃO' DA NEOLOGIA DO PORTUGUÊS
}

\author{
PORTUGUESE NEOLOGY 'DIDACTIZATION'
}

Fosé Cambuta*

Instituto Superior Politécnico Católico do Huambo, Huambo, Angola

Resumo: 0 artigo que ora apresentamos é a síntese de um longo percurso de investigação que culminou na apresentação da tese de doutoramento em neologia. Ele é uma reflexão sobre a neologia do Português em Angola. Uma vez que Angola é um complexo de línguas e culturas, este estudo sobre neologia circunscreveu-se apenas à Zona Linguística Umbundu (ZLU), zona Centro-Sul de Angola. A investigaç̦ão incidiu sobre o comportamento linguístico do Português no contacto com a língua Umbundu para se aferir a necessidade do ensino quer do léxico quer da neologia do Português. 0 objectivo deste estudo é a reflexão sobre o fenómeno da neologia e, muito particularmente, sobre a sua didactização em contextos escolares.

Palavras-chave: didactizaç̣̃o; neologia; neologismo; Umbundu; Português.

Abstract: This article is the synthesis of a long-way research which has crowned with the doctoral thesis which reflects upon the Portuguese language neology in Angola. . Since Angola is a multilingual and multicultural country, this research is circumscribed to Umbundu Linguistic Zone (ULZ), to Angola Centre-Southern. The research was especially about the Portuguese linguistic behavior in contact with Umbundu Language for checking the teaching need of Portuguese lexical and neology. The aim of this study is to reflect on the phenomenon of neology and, in particular, on its didactics in school contexts.

Keywords: Didactization; Neology; Neologism; Umbundu; Portuguese.

* Doutor do Instituto Superior Politécnico Católico do Huambo - ISPOC, Huambo, Angola; kambutaafroangojoseph97@yahoo.com

hitrp://dx.doi.org/10.11606/issn.2236-4242.v32i3p25-44 
Linha D’Água (Online), São Paulo, v. 32, n. 3, p. 25-44, set.-dez. 2019

\section{Introdução}

O ensino da neologia como componente complementar ao ensino da gramática podia reger-se pelos pressupostos de base subjacentes ao ensino da gramática e do léxico. $\mathrm{O}$ ensino da gramática nas suas diversas componentes (oralidade, leitura - aspectos fonológicos, morfologia e sintaxe) tem como finalidade introduzir o aluno na manipulação da língua seja ela materna, L2 ou estrangeira. Esta operação linguística possibilitará a chamada consciência linguística (linguistic awareness) que é um conhecimento ganho quando o aluno junto da consciência implícita adquire a capacidade de olhar para a língua e compreender que ela é um sistema a explorar em várias dimensões: fonológicas, morfológicas, sintácticas, semânticas, pragmáticas e por diante (VILELA, 1995).

Os alunos adquirem a consciência linguística quando "evidenciam capacidades metalinguísticas, uma vez que assumem já uma perspectiva distanciada e não holística do conhecimento da língua" (DUARTE, 2010, p. 12). A consciência linguística conduz à competência linguística que representa para o aluno o estágio mais elevado na manipulação, reflexão e juízo crítico e produção de enunciados mais especializados para uma contribuição profícua para qualquer comunidade linguística. A presente reflexão pretende dar o seu contributo na evidenciação da necessidade e da possibilidade da didactização da neologia nos ambientes escolares e da sua inclusão nos programas acadêmicos.

\section{0 ensino da neologia}

Se o estudo do léxico abre perspectivas para outras subestruturas da gramática $\mathrm{da}(\mathrm{s})$ língua(s), o estudo da neologia dá as mesmas possibilidades. Como alguns linguistas o sublinharam, as unidades lexicais da língua que um falante utiliza, aprendeu-os no quotidiano, num processo de escuta/fala (DUARTE, 2010; CORREIA E ALMEIDA, 2012). O mesmo acontece com a neologia. Ela é perceptivel e detectável, como afirmam Correia e Almeida (2012, p. 25) "no nível da fala, ao qual pertencerão durante algum tempo".

Numa era da informação, da informática e da expansão de uma consciência multicultural em que as unidades lexicais das línguas facilmente viajam de uma 
Linha D’Água (Online), São Paulo, v. 32, n. 3, p. 25-44, set.-dez. 2019

língua para outra, considerada a capacidade da sua imposição no meio (internacional, nacional ou regional) do seu uso, a percepção, o reconhecimento, a identificação, o estudo e o ensino da neologia é uma tarefa que a Linguística moderna não pode prescindir. Neste processo, tem grande responsabilidade a actividade para a feitura de dicionários gerais e académicos ou escolares actualizados, o trabalho de um estudo permanente de localização de neologismos que sejam a base do trabalho didáctico numa aula de neologia. A criação destas condições viabiliza o trabalho do docente na leccionação da neologia.

É uma necessidade e uma urgência o trabalho com os neologismos, pois o nosso mundo é cada vez mais criativo e, por conseguinte, também mais exigente em termos de comunicação. A percepção de elementos novos na língua depende do conhecimento explícito desta mesma língua por parte do falante. Um dos instrumentos didácticos que contribui para esta consciência linguística é o dicionário.

A didáctica da neologia, ao mesmo tempo que se serve dos dicionários para a confirmação da natureza de uma unidade lexical com ocorrência nalgum texto, pode ser também um grande auxílio na observação, percepção, deteç̧ão da neologia da língua; a colecção de novos textos, as várias tipologias de textos, quer em contextos escolares, quer em contextos extra-escolares, servem para a observação de novas unidades pertencentes à língua corrente, ou pertencentes a um nível de especialização, banalização ou vulgarização (estes últimos conceitos tomados tal como são entendidos por Robert Galisson (1978) e por Teresa Lino (1990). O neologismo é uma entidade linguística que não surge aleatoriamente; apesar de ser um elemento novo na língua, ele aparece mediante processos específicos e diversificados na língua.

A neologia sendo parte importante do estudo das línguas reclama por um estudo sistemático e por uma didactização em meios académicos. $\mathrm{O}$ neologismo sendo uma unidade lexical nova na língua inscreve-se num conjunto de normas e estratégias linguísticas de cada língua natural. Por isso, todo o neologismo pode ser uma base importante de aprendizagem das problemáticas linguísticas que têm o léxico como base sobre o qual delineiam os seus pressupostos teóricos e base material de reflexão e de labor heurístico. 
Linha D’Água (Online), São Paulo, v. 32, n. 3, p. 25-44, set.-dez. 2019

\section{Dificuldade de elaboração de um modelo do processo ensino-aprendiza- gem das novas unidades lexicais do Português em Angola}

O contexto social angolano é marcado por uma história que, mais do que ajudar a construção de um sistema educativo eficiente e proficiente, lança grandes desafios ao processo educacional em curso. Um destes factores é a guerra que, em décadas de persistência, descentralizou em sentido negativo várias famílias angolanas. A desestabilização das redes familiares deu origem a deslocações das identidades culturais. Se, como temos vindo a afirmar, a cultura exprime-se no léxico e o léxico, por sua vez, veicula a cultura num movimento binómico de indissociabilidade entre os dois elementos (ZARATE, 1995; BERTINETTI E OSÓRIO, 2015), então as deslocações culturais originadas por um processo progressivo forçado duma desestruturação mecânica não só são nocivas ao próprio progresso social, mas também impeditivas do processo de desenvolvimento ao nível da escola.

Este argumento que acabámos de expor fundamenta-se num outro que quiçá seja o mais importante e o mais problemático. Trata-se da realidade angolana do multiculturalismo e do respectivo plurilinguismo ou bilinguismo. Estas problemáticas já foram objecto de exploração, onde foram abordadas questões relacionadas com a situação linguística de Angola. O multiculturalismo ao mesmo tempo que significa, e, é sem dúvida, uma grande riqueza nacional é também um grande desafio na definição das políticas linguísticas do país.

O artigo de Irene Guerra Marques, em 1985, intitulado Algumas considerações sobre a problemática linguistica em Angola já tinha definido alguns desafios com que se confronta a política linguística em Angola. A sua análise apresentava como questões problemáticas a divisão, linguisticamente falando, da sociedade angolana em duas: a sociedade dos que têm o Português como L2 (são a maioria e vivem nas zonas suburbanas e rurais) e a sociedade para quem o Português é língua materna (L1). Em segundo lugar, apontava como desafiante a questão da integração da criança angolana que aprende o Português na escola como L2 e a sua integração num mundo conceptual totalmente novo face à novidade da língua. Em terceiro lugar, o facto de em Angola não haver o ensino das línguas nacionais e/ou em línguas nacionais (MARQUES, 1985, p. 205-224). 
Estas questões levantam outros problemas decorrentes da própria dinâmica social linguística de Angola. A questão não é nova. Contudo, ela é assaz crucial para os linguistas angolanos. Trata-se do resultado de um olhar sociolinguístico actual do país que apresenta um contexto já referido por Irene Marques e que ainda hoje parece prevalecer. Ou seja, a dificuldade está em perceber como se pode classificar linguisticamente a sociedade angolana em relação ao Português. Pode afirmar-se que o Português em Angola é L1? Do mesmo modo, pode afirmar-se em justa medida que o Português em Angola é L2?

Esta complexidade da realidade sociolinguística angolana desencadeia nos linguistas angolanos um grande desafio para um debate que ainda está no seu início e que precisa, por isso, de ser estimulado e ser levado a sério, um debate franco e responsável para se poder preconizar aquela fecundidade intelectual da investigação que venha dar a sua contribuição no caminho da (re)definição da importância da Língua Portuguesa e das línguas nacionais no contexto dos Povos na sociedade angolana. Este caminho é, certamente, íngreme e penoso, pois exige um esforço da parte dos linguistas angolanos de trabalhar na investigação, não somente na área da linguística, mas também da sociolinguística, da própria sociologia e antropologia que podem ser ciências auxiliares à Linguística bantu.

$\mathrm{Na}$ conjuntura dinâmica destes problemas há um outro desafio sociolinguístico em Angola. O repto está relacionado com a própria condição do aluno ou do aprendente angolano em relação ao seu ambiente social. Todo o falante do Português em Angola, no uso quotidiano do Português está condicionado por um factor determinante na formação da sua identidade linguística. $\mathrm{O}$ aluno ou o aprendente angolano está na zona de interface entre o Português Europeu (PE) e o Português do Brasil (PB). Este condicionalismo envolve o plano fonético-fonológico, morfológico, sintáctico e semântico-pragmático. Hoje, em Angola, por causa dos media, a influência dos falares do Brasil tem uma forte presença. Quotidianamente, os alunos são confrontados com novos problemas e novas dificuldades originadas da variação linguística do Português. Do ponto de vista didáctico estas dificuldades colocam um grande repto ao aluno e ao docente.

O que se disse até aqui diz respeito ao sujeito destinatário do processo do ensino/aprendizagem. $\mathrm{O}$ aluno deste tipo vive situações e circunstâncias que não 
Linha D’Água (Online), São Paulo, v. 32, n. 3, p. 25-44, set.-dez. 2019

podem ser olvidadas pelos linguistas muito menos pela autoridade que superintende a educação de qualquer país. No entanto, outro repto que impõe restrições ou estorva o processo ensino/aprendizagem em Angola é a condição do professor. Os reptos mencionados em cima encontram uma grande implicação na actividade didáctica do docente.

Quer dizer, diante de um ambiente académico multicultural e, por conseguinte, multilingue, considerando as três tipologias de alunos que se possam encontrar nas escolas angolanas, emergem alguns condicionalismos que podem determinar o êxito ou o insucesso do professor. Por exemplo, um professor de Língua Portuguesa em Luanda pode ser, muitas vezes, confrontado com novas realidades linguísticas no estudo do léxico ou da neologia do Português. A razão de tal situação deve-se ao facto de que, um estudo sobre o léxico e sobre a neologia de Angola exigiria, em parte, do docente noções elementares das línguas nacionais angolanas.

Hoje, a neologia do Português em Angola vem maioritariamente dos fenómenos de contacto e de interferência linguística entre o Português Europeu (PE) e as línguas nacionais. Esta constatação permite observar que a neologia do Português em Angola é, acima de tudo, uma neologia resultante do encontro do Português Europeu (PE) com o mosaico das culturas angolanas.

A neologia encontra na lexicultura o seu ambiente fértil. O encontro do PE com as 41 línguas que compõem o xadrez linguístico angolano, do mesmo modo que é um grande desafio para o Português é também um encontro transformador, pois o falante dumas destas áreas linguísticas, ao assumir os conceitos em Português e ao traduzir em Português os conceitos da sua língua, protagoniza um produto de um processo que é algo que, sem dúvida, sofreu transformações.

Neste encontro de concepções do mundo transmitidas pelo léxico presente nas duas culturas - a do aprendente e a portuguesa - opera-se, certamente, o que se pode chamar choque cultural. Por isso, em tal contexto académico o professor tem a exigência da verificação da diversidade cultural e linguística numa sala de aula. No entanto, não se pode pensar que um trabalho deste tipo seja menos importante; é um labor acrescido à actividade da docência do professor. Contudo, ele é uma exigência da índole própria do seu labor. Daí que, a concepção de um modelo do processo educativo ensino/aprendizagem do léxico e da neologia em Angola 
Linha D’Água (Online), São Paulo, v. 32, n. 3, p. 25-44, set.-dez. 2019

esbarra-se com a exigência do contexto sociolinguístico. O desafio lançado pelo multilinguismo coloca a exigência de uma abertura ao plurilinguismo por parte do docente e reenvio para um trabalho permanente de investigação sobre as línguas nacionais que deve estar sempre actualizado sobre os resultados publicados e sobre os estudos mais recentes sobre a situação das línguas bantu angolanas.

Por isso, levanta-se uma questão: que modelo educativo do processo didáctico ensino/aprendizagem das (novas) unidades lexicais do Português em Angola adoptar que seja capaz de manter a autonomia ou o esforço do professor de Português na sua actividade e que ao mesmo tempo tenha possibilidade de se dar conta de aspectos que dizem respeito ao aprendente ou ao aluno, como, por exemplo, a sua proveniência linguístico-cultural, para melhor fazer frente às barreiras linguísticas quer do lado do docente quer do lado do aluno ou aprendente da língua?

$\mathrm{Na}$ verdade, não é sem dificuldades que se pode responder a esta questão, pois diante de um texto que contenha algumas unidades lexicais de várias línguas nacionais, não é fácil exigir do docente o domínio de todas elas. E, logo à partida, se tal acontecer, é um desafio para o docente.

\section{Os desafios da didactização dos neologismos}

Do que ficou exposto em cima, conclui-se que o desenvolvimento do processo ensino/aprendizagem do léxico não é uma tarefa linear. É um processo que comporta vários reptos e é envolvido por factores muito diferenciados que o condicionam ou podem condicionar. Os primeiros factores são os elementos do jogo ou do processo: o professor e o aluno. Da relação destes dois elementos depende também o seu sucesso. No entanto, tal como acontece com o léxico, o maior desafio da didactização da neologia é a questão do método.

Relativamente a esta problemática, Ferreira (1985) pô-la num contexto de problematização, na moderna pedagogia do léxico. Uma das razões que têm sido evocadas para negar a exequibilidade da didactização do léxico é uma concepção que o considera um conjunto destruturado e desordenado de palavras e de carácter ilimitado. Tomando os pressupostos e últimos resultados da Lexicologia contemporânea e partindo da afirmação de que 
le lexique, même s'il est pratiquement illimité, répond à des lois d'organisation structurale et que la connaissance de ces lois permet de mettre au point un enseignement systématique. Les mots, en effet, ne sont pas les éléments épars d'un inventaire désordonné : ils se situent les uns par rapport aux autres par le jeu de relations et d'oppositions qui seules leurs confèrent une fonction linguistique, au niveau de l'organisation du signifié (DEBYSER, 1972, p. 5).

Ferreira conclui que, de facto,

um dos principais objectivos do ensino de uma língua quer materna quer estrangeira é o desenvolvimento da competência lexical do aluno, aumentando o conhecimento que ele possui das estruturas fundamentais da língua e desenvolvendo o seu campo expressivo. A necessidade de ensinar o vocabulário é, pois, um facto incontestável (...) (FERREIRA, 1985, p. 35).

Nesta linha de ideias, a didactização do léxico passa, não mais pelo aprendizado através da memória ou memorização desordenada das novas unidades lexicais, mas pela sua gradual estruturação desde as estruturas de campos lexicais. Esta prática de sistematização possibilita uma assimilação que se processa de modo coerente e pouco penoso. Uma linha assim delineada descentraliza a sua atenção na retenção do vocabulário, privilegiando o aspecto quantitativo e passa para uma abordagem qualitativa que evidencia mais a aquisição pelo aluno da competência lexical em função da competência linguística (FERREIRA, 1985, p 36).

Esta perspectiva vem de Galisson que, segundo Debyser

a mis au point une pédagogie de l'enrichissement méthodique essentiellement fondée sur un apprentissage rationnel des synonymes. Grâce à ce travail, les étudiants étrangers et les professeurs, et pourquoi pas les maîtres de classes françaises, disposeront d'une méthode nouvelle pour clarifier des ambigüités que les dictionnaires usuels, même les dictionnaires de synonymes, ne lèvent pas toujours. (DEBYSER, 1972, p. 6).

Em todas estas afirmações e perspectivas está evidenciado o problema do método. Contudo, para a realidade nacional angolana esta questão é originada pelo problema já exposto relacionado com o bilinguismo nacional e a diversidade 
Linha D’Água (Online), São Paulo, v. 32, n. 3, p. 25-44, set.-dez. 2019

cultural. Marques (1985) já tinha identificado o problema, quando afirmou em termos de proposta, que

todo o trabalho ao nível da problemática linguística no nosso país deve ser orientado a partir de, e em função de uma situação de plurilinguismo nacional e pluri ou bilinguismo individual. $\mathrm{O}$ reconhecimento e tratamento adequado desta realidade constituem a base para a promoção e utilização das línguas nacionais em todos os domínios e situações (de comunicação) e para o ensino mais eficaz da língua portuguesa. (MARQUES,1985, p 212).

Julgamos que, relativamente à didactização dos neologismos no Português falado em Angola, é um grande desafio.

O primeiro desafio, se se enquadrar a questão nesta perspectiva, está no facto de que, quando se fala da neologia do Português em Angola, não se fala de uma realidade linguística homogénea, mas de uma realidade acidentada que exige do professor competências variadas. No fundo da questão está aquilo que constou das propostas de Marques para o ensino do Português. Marques (1985, p. 214) sugeriu que - esclarecendo o seu método de análises contrastivas no ensino da língua - os professores de Língua Portuguesa, por inerência da exigência do seu trabalho, se esforçassem pela obtenção de um conhecimento básico das características das línguas bantu angolanas.

A nosso ver, aqui reside o problema. A questão tem a ver com o facto de que, em Angola, a maioria dos professores de Língua Portuguesa, não tem um domínio das línguas nacionais. E, por vezes, nem sequer da sua língua local. Nestas circunstâncias, como se poderá ensinar o léxico ou a neologia, principalmente, aquela neologia proveniente da língua em contacto e de marcas de lexicultura? E o desconhecimento da língua é acompanhado, em muitos casos, do desconhecimento da própria cultura local.

O acesso àquilo que Bordieu (1977 e 1984) chamou cultural capital (SWANN - DEUMERT - LILLIS - MESTHRIE, 2004, p. 68) entendido como "different forms of knowledge, values, language and meaning that individuals come to possess through their everyday living in specific social contexts", é feito pela língua. A didactização da neologia exige aspectos concretos de uma comunicação endógena e exógena. Este tipo de comunicação requer a abertura a um conjunto de saberes 
Linha D’Água (Online), São Paulo, v. 32, n. 3, p. 25-44, set.-dez. 2019

linguísticos, ainda que elementares, mas que capacitem os professores de práticas heurísticas no estudo das línguas e da neologia em particular.

O outro repto pode estar localizado na estruturação dos materiais e nos métodos de ensino do Português em Angola. O estudo do Português em Angola nos ensinos primário e secundário em todos os seus ciclos está centrado no uso de manuais de leitura. Coloca-se a questão da elaboração dos manuais. Quem os elabora? Que grau de competências, em termos de conhecimento do capital cultural angolano, possui quem elabora os manuais? Que conhecimento tem do destinatário destes manuais? Ou seja, que tipo de competências se pretende atingir, em relação aos alunos, com estes manuais? Este é um factor determinante para que o processo ensino/ aprendizagem não só da neologia, como também do léxico seja um processo com resultados preconizáveis e auguráveis. Pois sendo os manuais o suporte primeiro do professor, o seu modelo tem de conceber as várias sensibilidades e contemplar as diversas realidades nacionais das línguas e das culturas nacionais angolanas.

\section{Processo ensino-aprendizagem da neologia do Português em Angola: proposta de um modelo}

Se se considerar que um dos escopos do Português em Angola é garantir aos estudantes competências lexicais para a construção da competência comunicativa, considerando que a natureza do acto comunicativo está dependente não somente de factores internos como também externos, então afigura-se que a contextualização dos manuais de Português e a sua adequação à realidade nacional angolana seja um factor decisivo para o êxito dos seus conteúdos. Este ponto parece não oferecer muitos obstáculos, pois os manuais analisados evidenciam este cuidado, embora ainda não em grau augurável.

Por isso, o nosso desafio da elaboração de uma proposta de um modelo do ensino da neologia do Português em Angola está centrado na proposta do método de elaboração dos manuais para o ensino da Língua Portuguesa em Angola. Este pressuposto julgamo-lo importante e fundamental porque, a realidade dos manuais vigente para o ensino do Português no país evidencia maioritariamente o conhecimento, por parte dos seus autores, do ambiente cultural Kimbundu. Deste 
Linha D’Água (Online), São Paulo, v. 32, n. 3, p. 25-44, set.-dez. 2019

modo, a maioria das novas unidades lexicais provenientes de outras línguas nacionais são de difícil compreensão.

Esta dificuldade é visível na definição de unidades lexicais, em certos dicionários, que pretendem incorporar as diversas significações do espaço lusófono angolano: algumas unidades lexicais são confundidas com as do Kimbundu. Nestes casos, os dicionários definem essas unidades lexicais a partir do Kimbundu. Provavelmente, os autores das definições conhecem melhor esta língua bantu angolana e não têm conhecimento das outras línguas.

Os manuais didácticos são nacionais, isto é, não há manuais regionais. Diante de um aluno que conheça bem a sua língua e se confronte com uma informação de outra língua, duas alternativas se colocam: ou assume o erro ou fica confundido. Para o professor, o repto consiste em saber que procedimento metodológico deve tomar diante de tal situação, se for capaz de detectar o erro. Ele também tem duas possibilidades: ou corrigir o erro ou deixá-lo passar. O mesmo acontece na consulta de um dicionário.

Por esta razão, a nossa proposta de um modelo teórico do processo ensino/ aprendizagem da neologia do Português no país está alicerçada sobre uma perspectiva centrada no método de elaboração dos manuais de Língua Portuguesa e na preparação dos professores para o ensino do Português quer seja L1 ou L2 em relação às línguas nacionais.

Deste modo, advoga-se a aplicação de uma metodologia na elaboração dos manuais de Português que consiga realizar, mediante uma mais ampla participação de peritos, não somente em questões de Língua Portuguesa, mas também em questões das nossas línguas e culturas nacionais. Esta possibilidade permite a maior abrangência no estudo do léxico e da sua inovação nas diversas sensibilidades linguísticas existentes no país. Além disso, ela pode ser um estímulo à investigação nesta área. Deste modo, a política linguística do Português no ensino devia fazerse pela reconsideração da proposta da elaboração de manuais mais participada.

Este procedimento metodológico, na actualidade, em Angola, já é possível, se atendermos ao número de trabalhos que se têm vindo a elaborar na área da Lexicologia, Lexicografia e Terminologia, sobretudo nos estudos de Mestrado. Compreende-se que os trabalhos existentes ainda não são suficientes para garantir um conjunto de exigências que requeira o ensino da neologia. Contudo, eles, uma vez 
que têm vindo a ter alguma cobertura sob o ponto de vista das áreas linguísticas, no mapa linguístico de Angola, podem ser um ponto de partida de consideração e também de incentivo para novos trabalhos.

Neste sentido, é pertinente a criação de uma tradição que estabeleça uma estreita relação entre os linguistas lexicólogos, lexicógrafos ou terminólogos e principalmente os elaboradores de manuais de ensino não só de Língua Portuguesa, como também de outras áreas, e os professores do Português.

Esta ideia está subjacente na proposta de Bronkart (1985 e 2007). Para este autor, o ensino da língua deve fazer-se sobre a base de um conhecimento descritivo desta mesma língua. $\mathrm{O}$ autor entende que a didáctica da língua deve ter em consideração dois aspectos fundamentais: a adequação e a especificidade da língua (BRONKART, 1985, p. 48). Segundo o autor, "a didáctica da língua depende das concepções acerca do estatuto da língua nas suas relações com a representação do mundo e com as práticas verbais e comunicativas" (BRONKART, 2007, p. 134).

A relação entre os linguistas e os professores angolanos do Português é fundamental, pois, o trabalho dos linguistas, além de ser uma base essencial para os professores do Português, também pode ser um factor determinante na relação produção-consumo do produto linguístico elaborado pelos linguistas no seu empenho e desempenho na investigação das línguas nacionais angolanas e do Português.

O estudo da neologia em Angola é uma necessidade. Além de possibilitar o desenvolvimento e o alargamento do capital lexical dos dicionários, dos alunos e de outros utentes da língua, ele pode funcionar também como um incentivo e um reforço ao gosto para o estudo e conhecimento das línguas nacionais e das tradições das culturas nacionais angolanas.

Por isso, uma vez que o ensino por meio de manuais de leitura tem por objectivo favorecer a maturidade intelectual ao aluno, a fim de que chegue a atingir uma consciência linguística que lhe permita adquirir competências lexicais e outras, é indispensável a visibilidade da interacção entre as culturas nos manuais.

Esta metodologia, além da sua proficuidade para o acto didáctico da língua, pode ser também, do ponto de vista sociológico, um princípio de unidade nacional; pode ser um reforço da unidade na diversidade linguística e cultural de Angola, pois todos passam a conhecer um pouco de todos através do estudo da inovação lexical do Português. 
Uma segunda proposta neste âmbito é a formação dos professores. Como já ficou afirmado anteriormente, o sucesso da actividade da docência depende, em grande medida, da relação professores-investigadores. Se esta componente é funcional para todas as áreas do saber humano, ela é muito mais exigência do ensino das línguas. Por conseguinte, o ensino do léxico do Português, em Angola, vai exigir um maior envolvimento dos professores do Português. A este respeito, Figueiredo (2004) sublinha justamente que

\begin{abstract}
se o ensino e aprendizagem da língua materna [ou não materna] é uma actividade sistémica, a análise das actividades, dos seus objectivos, dos seus processos de realização, dos seus resultados requer a elaboração de modelos heurísticos que permitam, por um lado, actuar e, por outro, fazer perguntas e formular hipóteses que conduzam à investigação das acções que se levam a cabo, com a finalidade de buscar os melhores caminhos possíveis. Por outro lado, estas mesmas práticas, baseadas em modelos explícitos que permitem a reflexão e a investigação, poderão ser também o ponto de partida não só da formação inicial, mas também da formação contínua e continuada. (FIGUEIREDO, 2004, p. 17)
\end{abstract}

Por isso, faz sentido a proposta que defende a criação de um instrumento auxiliar aos manuais de leitura para o ensino do Português, apoiando a actividade didáctica das novas unidades lexicais.

A consciência e competência linguísticas do aluno no processo ensino/aprendizagem, se de um lado depende do próprio aluno, por outro lado o docente é a fonte e o canal de transmissão deste saber. Tem sido um lugar-comum neste trabalho a afirmação da proficuidade do léxico para o desenvolvimento intelectual e social do aluno ou de qualquer utente da língua. Esta pertinência imprime um carácter de utilidade do ensino da Lexicologia. Por esta razão, a actividade didáctica do ensino do léxico não pode ser considerada um acto secundário ou dispensável, mas uma componente em estreita correlação com o ensino da gramática.

Em consequência, entendemos que uma proposta que convide e incentive os professores do Português em Angola à aquisição de competências no ensino das línguas passa também pela formação em Lexicologia. No entanto, visto que a maior parte das novas unidades lexicais do Português em Angola tem origem no 
Linha D’Água (Online), São Paulo, v. 32, n. 3, p. 25-44, set.-dez. 2019

quotidiano da população e no ritmo das suas culturas e tradições, os professores devem também adquirir competências na área da antropologia cultural angolana.

Assim, a competência linguística do professor do Português deve estar sensível à competência multilinguística das línguas nacionais angolanas. Para tal, é necessário - e esta pode ser uma terceira proposta - que haja, durante os concursos para manuais de leitura, um maior esforço de localização de obras (manuais) que melhor traduzam ou evidenciem a riqueza do pluralismo linguístico nacional e que integrem uma visão neológica da língua e o fenómeno do dinamismo do Português no país como contributo de novas descobertas linguísticas ou culturais.

\section{A questão do método no ensino da neologia}

A proposta metodológica que apresentamos é estritamente teórica. Não é nossa pretensão tratar de uma aplicação pragmática do método. Tem-se como objectivo (re)pensar que contributo pode ser dado ao processo ensino/aprendizagem do Português, no domínio do léxico e, mais especificamente, no domínio da neologia. Pretende-se contribuir para a construção de um ambiente de debate sobre uma problemática que, embora ainda seja de uma abordagem não muito comum em Angola, é, efectivamente, uma necessidade e uma urgência.

Pela proficuidade da neologia no contexto das línguas e das culturas nacionais no seu encontro com o Português (PE) em Angola, foi afirmada nos capítulos anteriores a necessidade do estudo da neologia do Português em Angola. O empenho necessário neste domínio não é um trabalho sem objectivos. Já nos debruçámos sobre a relação professor da língua-investigador das línguas e da relação produto-consumo. (Re)pensar o(s) método(s) do ensino da neologia do Português L2 ou L1 é contribuir para o enriquecimento da actividade pedagógica e educativa do professor de Língua Portuguesa em Angola.

A questão dos métodos em todas as áreas do saber tem sido uma problemática constante. Não obstante a sua pertinência para a exequibilidade, quer da acção educativa quer no campo da investigação, a sua definição tem sido das mais complexas e cruciais. A sua complexidade radica do facto de que ela varia de área para área e, por vezes, de temática para temática. No caso da Linguística, mais 
Linha D’Água (Online), São Paulo, v. 32, n. 3, p. 25-44, set.-dez. 2019

particularmente da Lexicologia, da Lexicografia ou da Terminologia, ela se impõe também com grande força, pois dela depende, em grande medida os seus resultados. O estudo da neologia e o seu ensino não estão isentos desta preocupação.

A nossa proposta teórico-metodológica do ensino da neologia em Angola define-se como um complemento ao método clássico do uso dos manuais. O nosso ponto de partida é baseado na proposta de Galisson (1983), de Ferreira (1985), de Vilela (1995) e de Quivuna (2014). Galisson preconiza um processo ensino/aprendizagem que considere uma perspectiva teórica e outra prática. De facto, todo o pragmatismo repousa sobre uma base teórica. Deste modo, o ensino/aprendizagem da neologia pressupõe uma componente teórica que assegure o seu trabalho pragmático.

Segundo Ferreira (1985, p. 74), “a aprendizagem do léxico deve ser, assim, uma caminhada até ao interior da estrutura lexical. [Assim], a magia do desconhecido, o delírio da descoberta do cerzido interno das estruturas lexicais prendem a atenção do aluno e fazem-no correr, com encanto, a aventura de descobrir os traços mínimos distintivos dos elementos lexicais".

Julgamos esta perspectiva fundamental pois o trabalho com a neologia exige uma frequente busca do interesse dos alunos. Neste sentido, um conteúdo capaz de suscitar alguma curiosidade que oriente os aprendentes para a descoberta da complexidade da estrutura lexical pode ajudar a programação ou planificação duma sessão de interesse dos alunos.

Vilela (1995) privilegia uma perspectiva mais pragmática que leve os alunos a aprender através do contacto com os textos e na interacção com os outros. Esta linha metodológica é, sem dúvida, muito profícua para a aprendizagem e, sobretudo, para o desenvolvimento do acervo lexical no vocabulário do aprendente. Um procedimento metodológico deste tipo foi também proposto por Quivuna (2014) no trabalho de aprendizagem do léxico.

A pedagogia da neologia encontra o seu enquadramento nestas perspectivas que acabámos de descrever. A neologia pode ser encontrada nos textos oficiais de aprendizagem. Por isso, uma metodologia alicerçada sobre esta prática possibilita o trabalho com a neologia e, ao mesmo tempo, encontra um conjunto de possibilidades de trabalho para a aula da neologia. 
Assim como o texto, instrumento de trabalho, abre inúmeras possibilidades numa aula de língua, assim também o trabalho com o neologismo dá acesso a uma multiplicidade de desenvolvimentos e de análise em todas as componentes da Semântica lexical e da gramática. Não é somente o trabalho com os dicionários que confere a sua exequibilidade. Pode-se estudar a gramática a partir do trabalho desenvolvido com os neologismos. Por exemplo, a partir dos neologismos formais Wanditombi ou Kaleluia é possível encontrar possibilidades concretas de trabalho desde as fonético-fonológicas até às semânticas pragmáticas. Com os neologismos é possível o trabalho de determinação dos campos semânticos. Um neologismo encerra em si mesmo um trabalho de gramática assaz diversificado. Por isso, Vilela (1995, p. 1316) considera que a ciência do léxico é bastante contígua à disciplina da gramática.

Assim, entendemos que, embora o trabalho com a neologia numa aula possa ser feito por meio do uso de instrumentos de trabalho, como, por exemplo, os manuais, ele deve ser desenvolvido de forma mais alargada. Hoje, a neologia está presente não somente no livro, mas também e, sobretudo na rua. Os painéis publicitários, as várias actividades comerciais que se desenvolvem online, os blogues são uma grande fonte de observação das novas unidades lexicais da língua. Por isso, a internet é, hoje, um suporte indispensável para uma actividade de observação de novos dados ou novos elementos da língua (MIYAKI, 2003, p. 215-238). Neste sentido a rua (painéis publicitários, jornais, revistas, placas de sinalização, etc) e a rede (MORITA, 2003, p. 267-276) são dois factores que podem contribuir para a dinamização de uma aula de neologia. Deste modo, podemos evocar a proposta de Quivuna que defende um processo de aprendizagem que privilegie também o trabalho individual do aluno (a autoaprendizagem).

Por isso, é importante que um estudo da neologia e o seu ensino privilegie não somente os manuais, mas também a internet. Os alunos têm de ser estimulados a protagonizar a cultura da cibercultura. Quer se trate de neologia especializada ou de neologia de língua corrente, o recurso à internet pode ser um factor indispensável para a dinamização do processo ensino/aprendizagem. Hoje, grande parte das novas linguagens da interacção social de grupos que, por vezes, evidenciam o dinamismo das línguas estão alocadas na nuvem da internet. 
Linha D’Água (Online), São Paulo, v. 32, n. 3, p. 25-44, set.-dez. 2019

Em 1993, Dília Ramos Pereira apresentou no IV Colóquio da AFIRSE um artigo intitulado Inovação lexical e didáctica do Português. O seu objectivo foi perspectivar para os estudos linguísticos, na sua dimensão gramatical, a proposta que ela mesma designou por "processo de investigação" como um dos métodos inovadores do processo didáctico ensino/aprendizagem da língua. Esta proposta defende a ideia dum processo ensino/aprendizagem que privilegie a promoção de um trabalho de investigação para os professores e para os alunos na aula de língua. A proposta fundamenta-se no resultado da observação feita pela autora, resumida nos seguintes argumentos:

1. A importância do domínio do léxico para a compreensão e produção de significações intencionadas nas mais diversas interacções comunicativas; 2 . O facto de quando se aprende uma nova palavra estar-se ao mesmo tempo a aprender múltiplos aspectos da gramática da língua, tanto mais que o significado preciso de uma dada unidade lexical só pode ser satisfatoriamente aprendido através das relações com outras unidades lexicais presentes no contexto frásico ou mesmo apenas no textual; 3. O contributo do alargamento do vocabulário para a reestruturação cognitiva do adolescente possibilitadora de uma nova abordagem (...); 5 . O facto de o léxico ser uma componente particularmente aberto à criação, à inovação e à renovação permitindo o alargamento do pensamento incluindo hipóteses, ideias, e perspectivas descentradas (...) (PEREIRA 1993, p. 361-362).

O processo de aprendizagem da neologia requer investigação contínua e criatividade quer para os professores quer para os alunos. Assim, é importante que o docente crie nos alunos a consciência clara de que a criatividade é um factor fundamental e elementar para a aprendizagem quer do léxico em geral quer da neologia. $\mathrm{O}$ desenvolvimento desta consciência nos alunos dará possibilidade de uma habituação não somente da interacção do aluno com o professor para confrontar o resultado da curiosidade e a confirmação ou infirmação do docente, no que diz respeito aos resultados da pesquisa do aluno em tempos extra-escolares pedidos pelo professor ou devidos à sua própria curiosidade, mas também de um trabalho autónomo e orientado metodologicamente para o alcance de uma meta concreta. Este percurso no seu todo prepara e potencia o aluno para um conjunto dinâmico de várias e novas abordagens e para uma heurística de novos campos de 
Linha D’Água (Online), São Paulo, v. 32, n. 3, p. 25-44, set.-dez. 2019

aç̧ão. Neste sentido, o aluno deve ser considerado "agente activo na construção do conhecimento" lexical (FIGUEIREDO, 2004, p. 17).

Hoje, as técnicas de fichas e visualizações têm tido uma grande presença e um grande impacto nas actividades didácticas das escolas de línguas (GANTIER, 1974). O seu uso permite a captação da atenção e da concentração do aluno em ambiente académico. Permite também a estimulação do interesse e o gosto pelo trabalho, um factor fundamental para o sucesso do aluno.

O uso de fichas laboratoriais, de acordo com os ciclos de estudos, pode estimular a capacidade de manipulação linguística de estruturas lexicais complexas; levar à descoberta das estruturas internas dos neologismos e, podendo assim fazer a promoção da consciência linguística e do desenvolvimento do vocabulário; e estabelecer uma relação entre os neologismos de diversos tipos e a sua distinção de acordo com a sua estrutura interna e a sua semântica contextual em ocorrência textual (CORREIA E LEMOS, 2005, p. 57-81; CORREIA E ALMEIDA, 2012, p. 75-100).

\section{Conclusão}

A nossa proposta de modelo do processo de ensino/aprendizagem da neologia como contributo ao estímulo, quer dos linguistas angolanos quer dos professores de Língua Portuguesa em Angola, está voltada para a elaboração participada dos manuais de leitura, para a preparação dos professores de Língua Portuguesa e, sobretudo, seguindo uma perspectiva que privilegie uma relação interactiva entre professores do Português e investigadores. Este princípio evoca o maior desafio da didáctica da neologia: o método. Ele é um factor crucial, mas particularmente necessário. Apesar das inúmeras dificuldades existentes na concepção de um modelo metodológico que assegure o ensino seja do léxico em geral seja da neologia em particular, ele é um elemento imprescindível. Por isso, a nossa proposta nesta questão está fundamentada e segue a proposta de Galisson e de Quivuna no ensino do léxico.

Portanto, o processo ensino/aprendizagem da neologia, em virtude da sua própria índole, não se pode cingir unicamente à sala de aula, ele deve funcionar também como processo-estímulo aos alunos. É também um trabalho de cultivo da curiosidade dos alunos. Este método consiste na compreensão de que, sendo o aluno um elemento 
Linha D’Água (Online), São Paulo, v. 32, n. 3, p. 25-44, set.-dez. 2019

com ambientes sociais variados (casa, rua, escola) onde procura realizar e satisfazer o seu processo de socialização, quaisquer actividades didácticas com neologia precisarão do recurso ao método de autoaprendizagem. Para o estudo da neologia, este método é assaz vantajoso, porquanto, a neologia das línguas é um caso quotidiano.

\section{Referências}

BERTINETTI, F. S. - OSÓRIO, P. (2015) As políticas educativas e linguísticas europeias e a componente cultural no ensino-aprendizagem do Português no estrangeiro: o caso do ensino do Português em França in: BRANCO, M. L. - BIBER, D., Representativeness in corpus design. In: Literary and Linguistic Computing 8/4, 1993, pp. 243-257.

BRONKART,J-P. Las ciencias del lenguaje: un desafío para la enseñanza? Paris: UNESCO, 1985.

BRONKART,J-P. La enseñanza de lenguas: para una construcción de las capacidades textuales. Desarrollo del lenguaje y didática de las lenguas, Buenos Aires: Miño y Dávila, 2007, 133-146.

CORREIA, M. - LEMOS, L. S. P. Inovação lexical em Português. Lisboa: Edições Colibri e Associação de Professores de Português, 2005.

CORREIA, M. - ALMEIDA, G. M. B. Neologia do Português. São Paulo: Parábola Editorial, 2012.

DUARTE, I. Sobre o conceito de consciência linguística. In: FREITAS, M. J. - GONÇALVES, A. DUARTE, I. (Coord.) Avaliação da consciência linguistica. Aspectos fonológicos e sintácticos do Português. Lisboa: Edições Colibri, 2010.

FIGUEIREDO, O. Didáctica do Português Lingua Materna. Dos programas de ensino às teorias, das teorias às práticas. Porto: Edições ASA, 2004.

GALISSON, R. Recherches de lexicologie descriptive: la banalisation lexicale, Paris : Nathan, 1978.

GALISSON, R. D'bier a aujourd'hui la didactique des langues étrangères. Du structuralisme au fonctionnalisme. Paris: CLE International, 1980.

CAMBUTA, J. A 'didactizaçãó' da neologia do Português 
Linha D’Água (Online), São Paulo, v. 32, n. 3, p. 25-44, set.-dez. 2019

GALISSON, R. Des mots pour communiquer. Éléments de lexicométhodologie. Paris: CLE International, 1983.

GANTIER, H. O ensino de língua estrangeira. Lisboa: Editorial Estampa, 1974.

LINO, T. Banco de Neologismos do Português Contemporâneo - Balanço de uma experiência. In: Letras de hoje n. 82 (Dezembro, 1990) 103-116.

MARQUES, I. G. Algumas consideraçôes sobre a problemática linguística em Angola. Luanda: INALD, 1985.

MIYAKI, N. A. M. A mídia como instrumento de ensino do português - língua estrangeira (PLE): uma janela para uma comunicação intercultural. In: GÄRTNER, E. - HERHUTH, M. J. P. - SOMMER, N. N. (Eds.). Contribuiçôes para a Didáctica do Português Lingua Estrangeira. Frankfurt: Verlag Teo Ferrer de Mesquita, 2003.

MORITA, M. O ensino de PLE via rede: algumas considerações. In: GÄRTNER, E. HERHUTH, M. J. P. - SOMMER, N. N. (Eds.). Contribuições para a Didáctica do Português Lingua Estrangeira. Frankfurt: Verlag Teo Ferrer de Mesquita, 2003.

PEREIRA, D. R. (1994) Inovação lexical e didáctica do Português. In: ESTRELA, A. - FERREIRA, J. (org.). Desenvolvimento curricular e didáctica das disciplinas. Actas. IV Colóquio Nacional de Lisboa, Association Francophone Internationale de Recherche en Sciences de l'Education (AFIRSE), Secção Portuguesa, (19-20 de Novembro de 1993), pp. 361-369.

QUIVUNA, M. Lexicologia aplicada ao Ensino do léxico em Português língua não materna. Lisboa: Colibri, 2014.

SWANN, J. - DEUMERT, A. - LILLIS, T. - MESTHRIE, R. A Dictionary of Sociolinguistics. Edinburgh: Edinburgh University Press, 2004.

VILELA, M. Léxico e Gramática. Coimbra: Almedina, 1995.

Recebido: 19/06/2019.

Aprovado: 3/09/2019.

CAMBUTA, J. A 'didactização' da neologia do Português 